\title{
An active atmospheric methane sink in high Arctic mineral cryosols
}

MCY Lau, BT Stackhouse, AC Layton, A Chauhan, TA Vishnivetskaya, K Chourey, J Ronholm, NCS Mykytczuk, PC Bennett, G Lamarche-Gagnon, N Burton, WH Pollard, CR Omelon, DM Medvigy, RL Hettich, SM Pfiffner, LG Whyte and TC Onstott

The ISME Journal (2015) 9, 1904; doi:10.1038/ismej.2015.112

Correction to: The ISME Journal (2015) 9, 1880-1891; doi:10.1038/ismej.2015.13; published online 14 April 2015

Since the publication of this article, the authors have identified an error in the reported values for $\mathrm{CH}_{4}$ oxidation rates calculated from the microcosm experiment (Table 1), which also affected the reported $Q_{10}$ values (on page 7 and Figure 3):

At $66 \%$ and $100 \%$ saturations, the $Q_{10}$ values fell within the range of $1.3-2.9$ values previously reported from incubation experiments carried out at atmospheric or elevated $\mathrm{CH}_{4}$ concentrations (Figure 3). In contrast, the $Q_{10}$ value was 8 at $33 \%$ saturation (Figure 3).

The revised text is:

At $100 \%$ saturations, the $Q_{10}$ values fell within the range of 1.3-2.9 values previously reported from incubation experiments carried out at atmospheric or elevated $\mathrm{CH}_{4}$ concentrations (Figure 3). In contrast, the $Q_{10}$ value was 6 at $33 \%$ and $66 \%$ saturations (Figure 3 ).

Table 1 and Figure 3 have been amended to reflect these changes.

The authors would like to apologize for any inconvenience this may have caused. 